\section{Kompaktier- und Granuliermaschine}

Di ie Alexanderwerk Gruppe stellt mit der Walzenpresse PP 150 C eine Spezialmaschine vor, die gezielt für die Anforderungen in der Chemie und Feinchemie entwickelt wurde. Dabei werden gleichermaßen die hohen Standards der Großkonzerne als auch der Spezialanbieter erfüllt.

Die neue Walzenpresse für die Anwendung im unteren Produktionsbereich sowie zur Herstellung von kleineren Chargen ist standardmäßig mit einer Durchsatzleistung von bis zu $400 \mathrm{~kg} / \mathrm{h}$ sowie zwei Antrieben je Walze ausgestattet und kann optional mit einem oder zwei Rotorfeingranulatoren bestückt werden. Durch den Aufbau des Walzwerks in Schwingkonstruktion sowie die weitgehende Verwendung von Standardkomponenten wird eine flexible Handhabung sichergestellt.

Die Kompaktier- und Granuliermaschine verfügt über die patentierte Combi-VentFeeder-Technologie. Diese spezielle Ausführung des Einspeisesystems sorgt für einen besonders wirtschaftlichen Betrieb der Anlage, da durch die verbesserte Entlüftung gröBere Produktmengen in den Walzenspalt eingespeist werden können. Diese Walzenpresse ist zudem mit einer vertikalen Anordnung

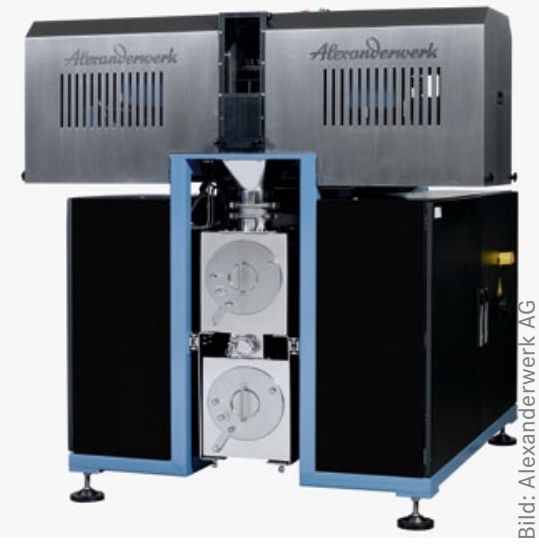

der Presswalzen mit einer horizontalen Produktzuführung ausgestattet. Dies bietet den Vorteil der gezielten Einspeisung definierter Produktmengen frei von Gravitationseinflüssen. Erwähnenswert ist ferner die moderne Steuer-und Regelungstechnik, die einen stabilen, umfassend überwachten und kontinuierlichen Prozess gewährleistet. Prozessparameter wie Durchsatzleistung, Schülpenstärke, Presskraft, Drehzahl etc. lassen sich so präzise und reproduzierbar einstellen.

Weitere Infos: Alexanderwerk AG, 42857 Remscheid, contact@alexanderwerk.com, www.alexanderwerk.com

\section{Vielseitig einsetzbarer Datenlogger}

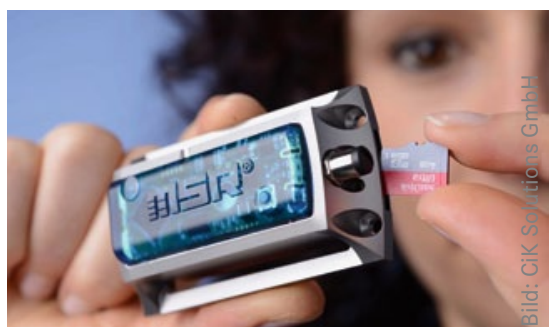

D er Datenlogger MSR145 von CiK Solutions kann jetzt mit bis zu fünf Sensoren der gleichen Messgröße (Temperatur, Feuchte oder Drucksensoren) ausgestattet werden - anstatt wie bisher mit einer Kombination verschiedener Sensoren. Damit erweitert sich sein Anwendungsbereich deutlich.

Außerdem besteht die Möglichkeit, diesen Multifunktions-Datenlogger mit einem externen Flüssigkeitsdrucksensor auszurüsten, was die Einsatzbreite im Bereich der Druckerfassung von Flüssigkeiten wie Wasser oder Öl weiter vergrößert . Darüber hinaus wurde der Temperaturbereich erweitert, sodass der Datenlogger nun auch für Anwendungen bis $-250^{\circ} \mathrm{C}$ einsetzbar ist.

Weitere Infos: www.cik-solutions.com

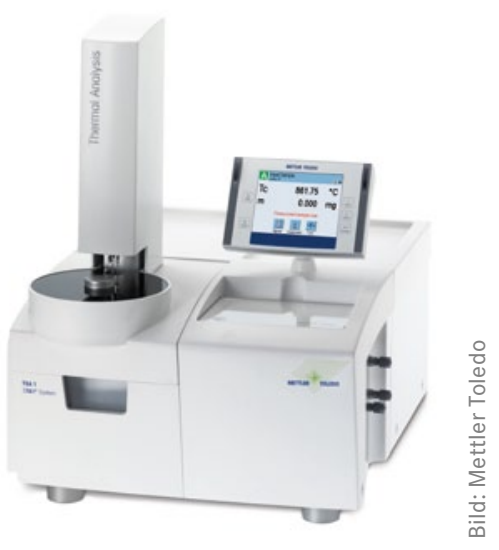

reich reicht von Raumtemperatur bis 1100 ${ }^{\circ} \mathrm{C}$. Zur hohen Genauigkeit trägt auch die genau definierte Atmosphäre im Ofen bei.

Weitere Infos: www.mt.com/ta-news 